Research Note

\title{
A Study on Fabrication and Structural Characterization of PbS Thin Films
}

\author{
${ }^{1,2}$ Mustika Wati and ${ }^{2}$ Kamsul Abraha \\ ${ }^{1}$ Jurusan Pendidikan MIPA, FKIP, Universitas Lambung Mangkurat, Banjarmasin, Indonesia \\ ${ }^{2}$ Jurusan Fisika, FMIPA, Universitas Gadjah Mada, Yogyakarta, Indonesia
}

\author{
Article history \\ Received: 03-10-2017 \\ Revised: 02-11-2017 \\ Accepted: 18-11-2017 \\ Corresponding Author: \\ Mustika Wati \\ Jurusan PMIPA, FKIP, \\ Universitas Lambung \\ Mangkurat, Banjarmasin, \\ Indonesia \\ Email:watika2018@gmail.com
}

\section{Introduction}

Lead Sulfide $(\mathrm{PbS})$ is a semi-conductor with a gap of energy and has a cubic structure, $0.41 \mathrm{eV}$. PbS Thin film is usually used in Infrared (IR) detectors. $\mathrm{PbS}$ is suitable for detecting radiation with wave lengths ranging from 1 to $3 \mu \mathrm{m}$ and can work in temperature ranging from 77 to $300 K$ (Choudhury and Sarma, 2009). PbS Materials have potential applications with high-speed changes, because they have exceptional properties against thirdorder nonlinear optics. PbS is also useful for making devices that require semi-conductors with small energy gaps as well as with optical absorption and emission in the red and near infrared spectrum areas (Ji et al., 2003).

\begin{abstract}
PbS}$ thin films are fabricated from $99.9 \% \mathrm{PbS}$ powder on glass substrates using the vacuum evaporation method. Some of the samples are then treated in an advanced process called annealing. Samples are annealed in temperatures of $80,100,120$ and $150^{\circ} \mathrm{C}$ for two h. Characterization using an X-Ray Diffractometer (XRD) resulted in values of lattice constant of the films ranging from $(5.782 \pm 0,010) \AA$ to $(5.919 \pm 0,006) \AA$. These values are quite different from the standard, probably because the films are stressed and strained. The grains have sizes ranging from $(266.440 \pm 0.001)$ $\AA$ to $(694.059 \pm 0.002) \AA$, where the greatest grain size was found as deposited thin film because it was directly condensed from powder vapor dung the deposition process and after they are annealed, the grain size becomes smaller. The average internal stress has values ranging from $(0.36 \pm 0,006) \times 10^{9} \mathrm{~N} / \mathrm{m}^{2}$ to $(3.247 \pm 0.010) \times 10^{9} \mathrm{~N} / \mathrm{m}^{2}$ and microstrain ranging from $(2,864 \pm 0.006) \times 10^{-3}$ to $(25.94 \pm 0,01) \times 10^{-3}$. It was found that the film which has the greatest stress and microstrain is the film with the annealing temperature of $150^{\circ} \mathrm{C}$, showing that the annealing process exerts force on the film following the rising of temperature. Use of a Scanning Electron Microscope (SEM) shows the surface pictures of the deposited thin film and the film annealed at $120^{\circ} \mathrm{C}$. Furthermore, the films and showed that the thickness of the deposited thin film is between 0.63 and 1.30 microns and the thickness of the film annealed at $120^{\circ} \mathrm{C}$ is between 3.37 and 4.34 microns. The best quality thin film from this research is that annealed at $120^{\circ} \mathrm{C}$, because it showed more peaks than the other samples. It can be concluded that the annealing process had effects
\end{abstract} Keywords: PbS Thin Films, Fabrication and Structural Characterization
Various methods are used in thin film fabrication, vacuum evaporation, cathode sputtering, chemical deposition, vapor deposition, combustion and anodic oxidation (Hass and Turner, 1959). For purposes of optical coatings, the vacuum evaporation method is commonly used. Use of appropriate shutters, diaphragms and rotation sector wheels and the possibility to move the substrate during deposition, the film may have a uniform thickness with different distribution as desired.

Microscopically, annealing affects the perfection of crystals, grain structure and size, chemical composition and state of stress of crystals (Wunderlich, 1976). The effect of the annealing process on crystal structure, grain size and state of stress has not been widely reported in 
existing studies, therefore it is necessary to have further investigation on this statement.

Characterization of the resulting thin film is absolutely necessary, because with different treatments, the optical or electrical properties attached to the film will also be different. Differences in these properties allow for use in different devices. Based on the resulting thin film characterization information, the film can be applied in the appropriate device.

Based on the above description, the problem raised in this research is the influence of the annealing process to the crystal structure. The purpose of this research therefore, is to investigate the effects of the annealing process on crystal structure, with the purpose of making $\mathrm{PbS}$ thin films with the vacuum evaporation method and annealing the resulting films with different temperatures. Furthermore, the study carries on characterization with $X$ Ray Diffractometer (XRD) and Scanning Electron Microscope (SEM) on the samples to obtain information about the quality, structure and morphology of thin films.

\section{Literature Review}

In 1954 Brebrik and Scanlon studied natural $\mathrm{PbS}$ with heat treatment at sulfur or lead vapor pressure, they also studied inter-diffusion of $\mathrm{Pb}$ in $\mathrm{PbS}$, obtained the inter-diffusion constant of $2.10^{-10} \mathrm{~m}^{2} / \mathrm{s}$ (Sukarjo, 1991). $\mathrm{PbS}$ crystals were made by Bloem as cited by Sukarjo (1991) regarding controlling the sulfur or lead environment pressure during annealing to see the effect on the concentration of the load carrier. After a single crystal is formed it is reheated, to obtain a more perfect crystal structure at temperatures $(800,900,1000,1100$ and 1200) ${ }^{\circ} \mathrm{C}$ each of which takes $(60,20,7,2) \mathrm{h}$ and 20 minutes.

According to Cheng et al, the $\mathrm{PbS}$ film is a polycrystalline that naturally has a Face Centered Cubic (FCC) structure. The well-illustrated peaks include the fields of Miller 111, 200, 220, 311, 222, 400, 331, 420, 422 and 511, its reflection is observed as a pattern in XRD. Peak strength and sharpness show that the film deposits on the glass substrate with different molarity have been crystallized well (Choudhury and Sarma, 2009).

Crystalline $\mathrm{PbS}$ produced from the Choudhury and Sarma (2009) research using chemical methods with 4 different molarities, i.e. $(0.25,0.50,0.75$ and 1.00$) \mathrm{M}$, indicates that the lattice a constant, increases gradually as molarity increases up to $0.75 \mathrm{M}$ and decreased at a concentration of $1.00 \mathrm{M}$, presumably this is influenced by the presence of grain strain. The increase in molarity was also in line with the increase of grain size to a concentration of $0.75 \mathrm{M}$ and decreased at a concentration of $1.00 \mathrm{M}$. Furthermore, Choudhury and Sarma (2009) reveal that the mean internal pressure and microstrain values show that at concentrations of $0.75 \mathrm{M}$ values are maximum.
The results of Ji et al. (2003), which made the $\mathrm{PbS}$ crystals by the hydrothermal method, show that the formed $\mathrm{PbS}$ has a cubic rock-salt structure with a lattice constant a $a=5.936 \AA$. Morphological characterization using SEM shows star-shaped PbS crystals. The results of the studies described above will be used as a reference to compare the results of this study with previous studies.

The development of thin-film technology began in about the middle of the $19^{\text {th }}$ century in 1852 , when W.R. Grove conducted an electric discharge study in a gas that is a symptom of the formation of a metal layer on the wall of a glow discharge tube around the negative electrode. Then in 1857 Faraday managed to create a metallic layer by evaporation method. Based on these findings, thin-film research has continued to develop to date and has even covered all areas of application, including in the electronics field (photo-making detectors, capacitors and microelectronics), mechanics (making of hard coatings as a protective material, i.e., wear and anti-corrosion), optics (manufacture of antireflectors and interference filters) and optoelectronics (making solar cells) (Iriani, 2000).

\section{Vacuum Evaporation Method}

The basic principle of the evaporation method is quite simple. The material to be deposited is heated at high vacuum until evaporated. The resulting vapor is compacted around the evaporator source and shaped as the desired film. Pressure during evaporation is lowered to the point where the mean free passage path of the molecule is greater than the dimensions of the vacuum chamber and the gas oxidation and absorption is kept to a minimum ( $p \approx 10-4 \mathrm{~mm} \mathrm{Hg}$ ). Evaporation takes place from heating of wires, strips and crucibles made from materials with high melting point. The problem of selecting suitable filaments or materials for the smelting plate has been investigated by Caldwell and Olsen et al. (Hass and Turner, 1959) Metals that can be used as heating elements are Wolfram (W), Tantalum (Ta), Molybdenum (Mo) and Niobium (Nb).

\section{Crystallization Through the Annealing Process}

In polymer science, the term annealing is used to describe the improvement of crystallization with heat to temperatures below the melting point which makes the crystal region grow, crystal perfection and change the crystalline structure to become more stable (Wunderlich, 1976). In this study, annealing can be regarded as secondary crystallization, meaning that this treatment gives the effect of crystallization after the first crystallization, in this case with vacuum evaporation. During grain growth, atoms move from one grain to another and cross the grain boundary, this process is a thermal activation process. 


\section{PbS Material as a Semiconductor}

$\mathrm{PbS}$ is a mixed semiconductor of lead element $\mathrm{Pb}$ (class IV) and elemental sulfur S (class VI). Due to its distinctive nature of having a power gap in the infrared energy order, with wavelength $\lambda(0.6-3) \mu \mathrm{m}$, the $\mathrm{PbS}$ semiconductor is widely used as an infrared semiconductor laser or as an infrared detector. The perfection of the $\mathrm{PbS}$ semiconductor is strongly influenced by the quantity of its constituent elements. If there is an excess of one component, then there will be impurity. If there is an excess of lead, it causes the formation of a negative type $\mathrm{PbS}$ semiconductor, otherwise if the excess is a sulfuric element the semiconductor will be positive (Sukarjo, 1991).

\section{Ray Diffraction $-X(X R D)$}

To find out the microstructure of the thin layer formed, analysis is generally done by using X-ray diffraction. When an X-ray strikes a material, the rays are scattered in all directions. The scattered X-rays are mutually reinforcing (constructive interference) when it comes to the material in which the atomic arrangement is organized. Whereas in materials with irregular atomic arrangement, the beam of light is mutually eliminated (destructive interference). The requirements for this test are: (i) the wave rate setting is done regularly and (ii) the wavelength of the beam is equal to the distance to be determined.

Figure 1 shows an X-ray beam with a wavelength $\lambda$, falling at angle $\theta$ on a set of distal crystal planes $d$. The reflected beam at angle $\theta$ can only be seen if the files of each adjacent field reinforce each other. Therefore, the additional distance of one beam is scattered from each adjacent plane and travels the distance according to the lattice difference, which is equal to the integer multiple of the wave length $n \lambda$. Reflection and mutually reinforcing conditions are expressed by:

$n \lambda=P O+O Q=2 O N \sin \theta=2 d \sin \theta$

Equation (1) is known by Bragg's Law and the angular value $\theta$ to meet the law is known as Bragg's angle.

Bragg's law in Equation (1) states that interference is constructive if the difference in the path of the X-ray diffraction beam is a multiple of wavelength, where $n$ is an integer $1,2,3, \ldots$ and $\lambda$ is the wavelength of X-rays and $d$ is the distance between fields and $\theta$ is the angle of diffraction. In general, the n-order diffraction of the $(h k l)$ plane with the spacing between plane $d$ can be regarded as first-order diffraction of the plane $(n h n k n l)$ so that Bragg's law is more well known in its form:

$$
\lambda=2 d \sin \theta
$$

In the experiment peaks are detected when Equation (2) is met, this means that the material structure is crystal. Conversely, if the peaks are not detected then the material structure is amorphous.

\section{Structural Characterization}

To determine the effects of the annealing processes on a crystal structure, the quantities to be investigated as indicators of the effect include lattice constants, grain size, average internal pressure and strain (microstrain).

\section{Determination of Lattice Parameters (Lattice Constants)}

Lattice constants for cubic structures can be determined using relationships:

$$
a=d\left(h^{2}+k^{2}+l^{2}\right)^{1 / 2}
$$

where, $d$ is the distance between plane $(\AA)$ and $(h k l)$ is the Miller fields.

\section{Grain Size}

The point in this study is a collection of crystal lattice. The grain size of the coating can be determined from the XRD results fractogram by using the Scherrer equation (Choudhury and Sarma, 2009):

$$
D=\frac{K \lambda}{\beta \cos \theta}
$$

where, $K$ represents form factor constants with a value of 0.94. $\lambda$ is the wavelength of X-ray used i.e. CuK $\alpha$ radiation $(\lambda=1.5406 \AA)$. $\beta$ is the half width of the width (Full Width at Half Maximum $=F W H M$ ) in radians.

\section{Average Internal Stress and Microstrain}

Average internal stress is a broad unity style, for a simple form (e.g. a simple cube), the area in question can be a chosen area that can represent the whole area. The average internal pressure on the film can be calculated by the equation:

$S=\frac{\left\{\left(a_{o}-a\right) / a_{o}\right\} Y}{2 \sigma}$

where, $a$ is the lattice constant of the thin film and $a_{o}$ is the lattice constant of the bulk sample, from the literature retrieved $a_{o}=5.936 \AA$. $Y$ is Young's modulus and $\sigma$ is Poisson's ratio. For $\mathrm{PbS}$, the value of $Y=70.2 \mathrm{GPa}$ and $\sigma$ $=0.28$ (Choudhury and Sarma, 2009).

From Equation (5) we can also determine the value of microstrain $\varepsilon$. Microstrain is a state because of the presence of pressure:

$\varepsilon=\frac{\left(a_{o}-a\right)}{a_{o}}$ 


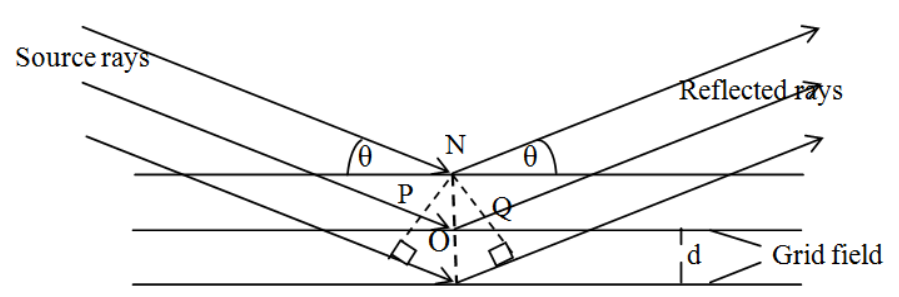

Fig. 1: Bragg diffraction of the crystal plane (Smallman, 1991)

\section{Research Method}

This research was conducted in a Physics Laboratory of Solid Matter FMIPA at Universitas Gadjah Mada, Yogyakarta. Broadly speaking, fabrication of $\mathrm{PbS}$ thin film by vacuum evaporation method (JEOL JEE-4X) has been done at a pressure of 1.10-3 Pa with a current of $35 \mathrm{~A}$, annealing at $80,100,120$ and $150^{\circ} \mathrm{C}$ using an Automatic Muffle Furnace with a current of $5 \mathrm{~A}$ and a voltage of $75 \mathrm{~V}$, each for $2 \mathrm{~h}$. Furthermore, structural characterization of the thin film was produced using X-Ray Difractometer (Shimadzu XRD-6000) with 40kV and 30mA current and a Scanning Electron Microscope (JEOL JSM-T300) with 25 $\mathrm{kV}$ acceleration voltage, $\times 1500$ surface enlargement and transverse magnification of $\times 2000$.

\section{Results and Discussion}

\section{XRD Results}

The results of characterization using XRD with X-ray is derived from $\mathrm{Cu}(\lambda=1.5406 \AA)$ source at $40 \mathrm{kV}$ and $30 \mathrm{~mA}$ currents, $10^{\circ}-90^{\circ}$ data range with scan speed $5 \%$ min, resulting in a spectrum as in Fig. 2.

The XRD pattern for $99 \% \mathrm{PbS}$ powder features wellillustrated peaks, indicating that the $\mathrm{PbS}$ powder is a crystal. The hkl plane which can be seen on the PbS powder XRD pattern includes the fields 111, 200, 220, 311, 222, 400, 331, 420, 422, 511; these Miller fields are very much in line with those of Choudhury and Sarma (2009). The deposited thin film peaks appear at $2 \theta=13^{\circ}$, after it is confirmed with Xbd pattern of $\mathrm{PbS}$ powder, at that angle there is no peak showing the $h k l$ plane for $\mathrm{PbS}$, it is concluded that the peak seen at the angle $2 \theta=13^{\circ}$ is not the peak of the PbS crystal, but from the substrate (glass) used. The pHS crystalline $h k l$ areas detected for the deposited thin films were at fields 111, 200, 220 and 222.

In the XRD pattern of annealing samples, there is no peak at the angle of $2 \theta=13^{\circ}$, this shows that the substrate peak is no longer detected by the annealing process, it is concluded that the annealing process gives effect the of loss of impurity. Based on confirmation with $\mathrm{PbS}$ powder crystals data, for thin films that have been annealing at $80^{\circ} \mathrm{C}$, the obtained $h k l$ fields include 111, 200, 220, 400 and 420. For PbS thin films which have undergone annealing process at $100^{\circ} \mathrm{C}$, the $h k l$ fields obtained are 111, 200, 220, 311, 422 and 511. For $\mathrm{PbS}$ thin films which are annealing at $120^{\circ} \mathrm{C}$, the $h k l$ fields are $111,200,220,311,400,420$ and 511. The
XRD pattern image shows more $h k l$ areas detected along with the temperature rise performed at the time of annealing. So, it can be said that the annealing process at 80,100 and $120^{\circ} \mathrm{C}$ has helped the crystal growing process after the first growth of the deposited thin film.

For thin films annealing at a temperature of $150^{\circ} \mathrm{C}$, resulting in fewer peaks when compared to other samples, the visible $h k l$ planes are 111, 200 and 220. This is presumably because at a temperature of $150^{\circ} \mathrm{C}$, some layers attached to the substrate evaporate resulting in defects and shrinkage on the resulting thin film. The notion of evaporating the coating when the temperature is increased is reinforced by looking at the results during the first experiment, where the annealing process is carried out at $400^{\circ} \mathrm{C}$ and after the sample is removed from the furnace, the substrate is clean, with the absence of a thin layer.

\section{Lattice Constants}

Equation (3) can be obtained by the value of lattice constant as in Table 1, which ranges from $(5.782 \pm 0,010)$ $\AA$ to $(5.906 \pm 0,009) \AA$. This value is slightly different from the lattice constant value obtained from the literature of $5.936 \AA$ (Choudhury and Sarma, 2009). The difference in the value of the measured lattice constant with the lattice constant value of the reference indicates that the film is under strain. The fractional lines are not always sharp (due to widening of the line) due to various tool factors such as gap size, test state and wavelength dispersion, but in addition, the lines can be widened because of lattice strain in the crystal diffraction area as well as the dimension limit (Smallman, 1991).

\section{Grain Size}

Based on the Scherrer formula as in Equation (4), the grain size is as shown in Table 1. The deposited thin film sample has the largest grain size compared to the other samples because the formed grain is a direct deposition of $\mathrm{PbS}$ powdery vapor. For The deposited thin film sample has the largest grain size compared to the other samples because the formed grain is a annealing samples at 8,100 and $120^{\circ} \mathrm{C}$ have smaller grain size and gradually increased in line with rising temperatures in the annealing process, suggesting that the annealing process helps to improve the crystallization structure. In the sample with annealing at $150^{\circ} \mathrm{C}$ it appears that the grain size decreases again, this is thought to be due to defects and shrinkage in the film due to the presence of some of the evaporating layer. 


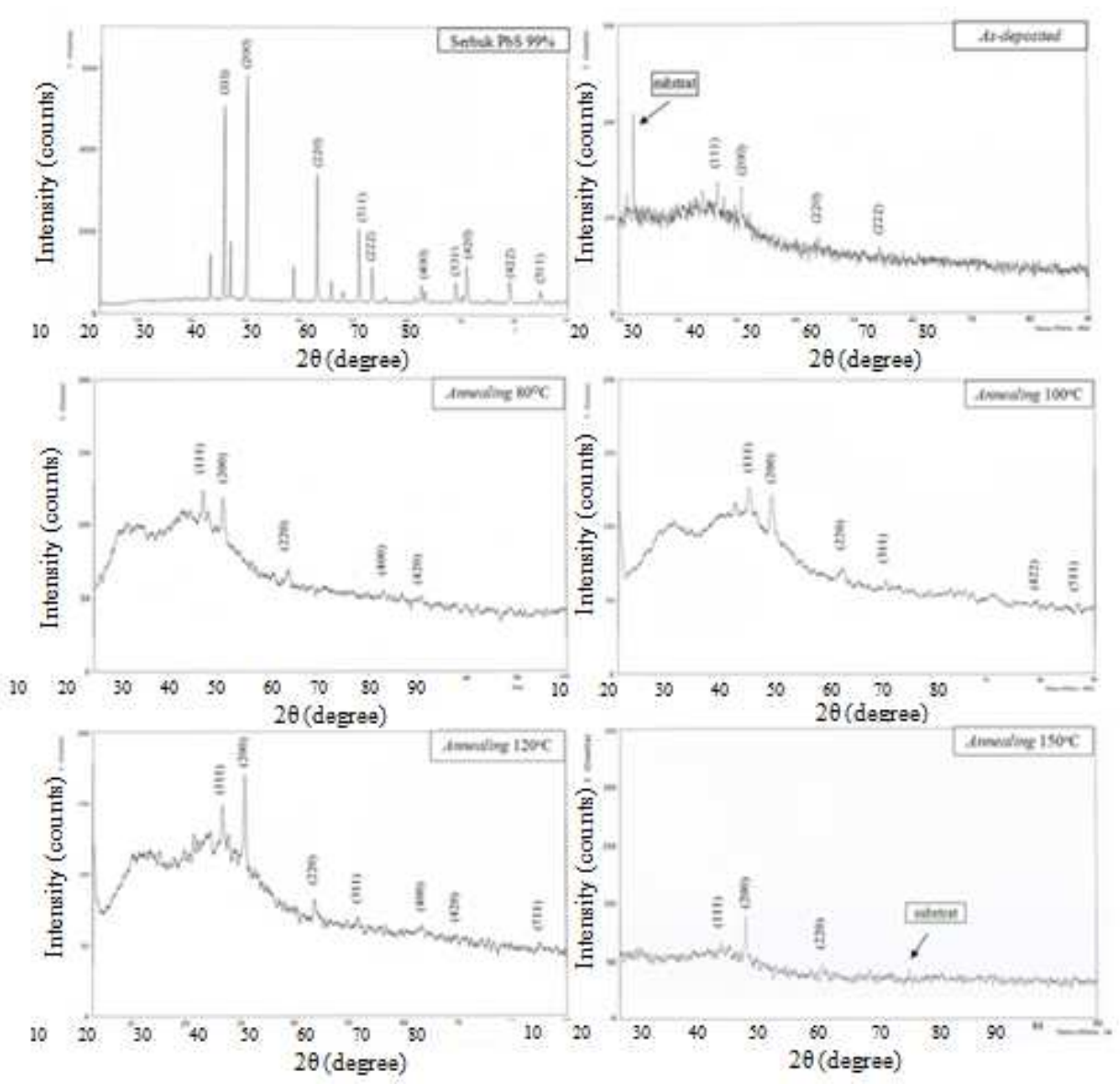

Fig. 2: XRD spectrum pattern

$\underline{\text { Table 1: Data results analysis }}$

\begin{tabular}{llccc}
\hline Sample & $\begin{array}{l}\text { Lattice } \\
\text { constants }(\AA)\end{array}$ & $\begin{array}{l}\text { Grain size } \\
(\AA)\end{array}$ & $\begin{array}{l}\text { Internal pressure average } \\
\left(\times 10^{9} \mathrm{~N} / \mathrm{m}^{2}\right)\end{array}$ & $\begin{array}{l}\text { Microstrain } \\
\left(\times 10^{-3}\right)\end{array}$ \\
\hline Powder & 5.919 & 515.104 & 0.364 & 2.864 \\
Deposited & 5.906 & 694.059 & 0.639 & 5.054 \\
Annealing $80^{\circ} \mathrm{C}$ & 5.838 & 266.440 & 2.068 & 16.509 \\
Annealing $100^{\circ} \mathrm{C}$ & 5.826 & 332.616 & 2.319 & 18.531 \\
Annealing $120^{\circ} \mathrm{C}$ & 5.860 & 351.696 & 1.605 & 12.803 \\
Annealing $150^{\circ} \mathrm{C}$ & 5.782 & 337.791 & 3.247 & 25.943 \\
\hline
\end{tabular}

Based on the data in Table 1 , the number of lattices contained in a single item can be calculated. For example, for powder samples with a lattice constant value of $(5,919 \pm 0.006) \AA$ and a grain size (515.104 \pm 0.002$) \AA$, a single grain of $\mathrm{PbS}$ powder consists of \pm 87 lattice crystals.

\section{Average Internal Pressure and Microstrain}

The average internal stress is calculated based on (5). From the data in Table 1, it appears that thin films that have been annealed experience greater pressure compared with the deposited thin film samples. This suggests that the annealing process exerts force to the sample according to the theoretical basis that the average internal pressure is a broad united force. The largest pressure samples are thin films that are annealed at $150^{\circ} \mathrm{C}$ and the smallest pressure sample was a thin film annealed at $120^{\circ} \mathrm{C}$.

The microstrain value is calculated based on Equation (6), the microstrain is the effect of the presence of pressure $S$, on the annealing samples that show greater pressure compared to the deposited thin film sample, so the effect is on the samples that have undergone this annealing larger microstrain as well. In accordance with the calculation of pressure on the sample, it appears that the thin film has the greatest value of microstrain i.e., the thin film annealed at $150^{\circ} \mathrm{C}$ has smaller microstrain value of thin film annealed at a temperature of $120^{\circ} \mathrm{C}$. 


\section{SEM Results}

Based on the data obtained, the samples that have been annealing at $150^{\circ} \mathrm{C}$, experienced the greatest pressure and microstrain and showed fewer peaks when compared with other samples. The samples subsequently selected to be characterized by using Scanning Electron Microscope (SEM) are as-deposited thin film samples and samples that have been annealing at $120^{\circ} \mathrm{C}$, as shown, the average value of internal stress and microstrain compared to other samples as well describes the better peaks.

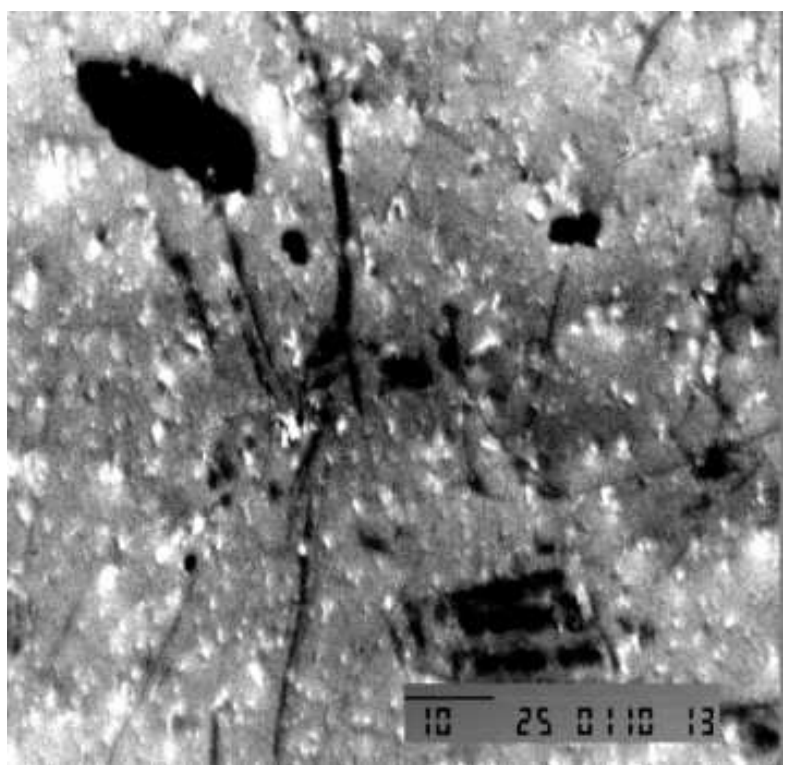

(a)
From SEM results obtained surface image for the deposited thin film samples and samples with annealing of $120^{\circ} \mathrm{C}$ as in Fig. 3 .

The thickness of the dispositioned sample is known by the transverse SEM position. For as-deposited samples, the thickness of the coating is $\pm(0.63-1.30) \mu \mathrm{m}$ as shown in Fig. 4(a) and the thickness of the sample with annealing at $120^{\circ} \mathrm{C}$ is $\pm(3.37-4.34) \mu \mathrm{m}$ as shown in Fig. 4(b). From Fig. 4 it appears that the thickness of the annealing sample layer with a temperature of $120^{\circ} \mathrm{C}$ is thicker when compared to the thickness of the asdeposited sample layer.

Fig. 3: (a) surface of the as-deposited sample (b) sample surface with annealing of $120^{\circ} \mathrm{C}$

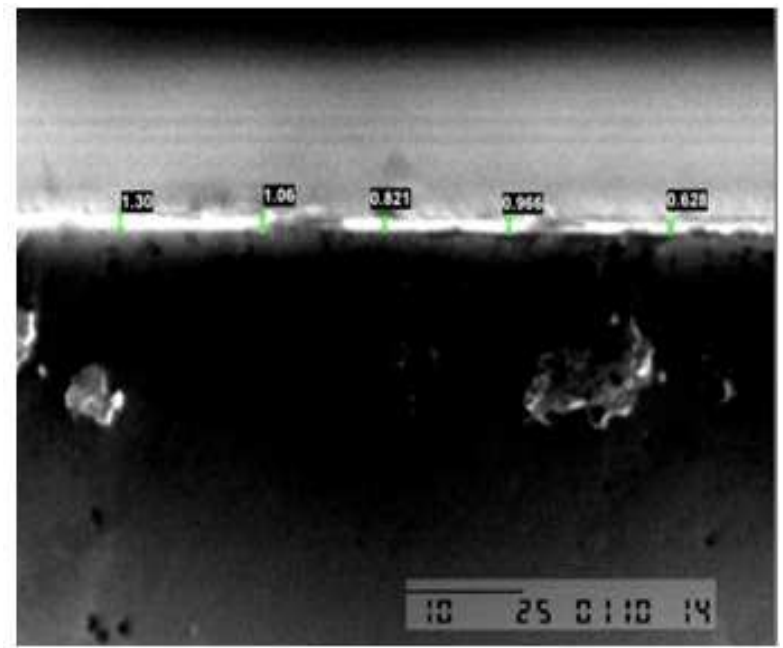

(a)

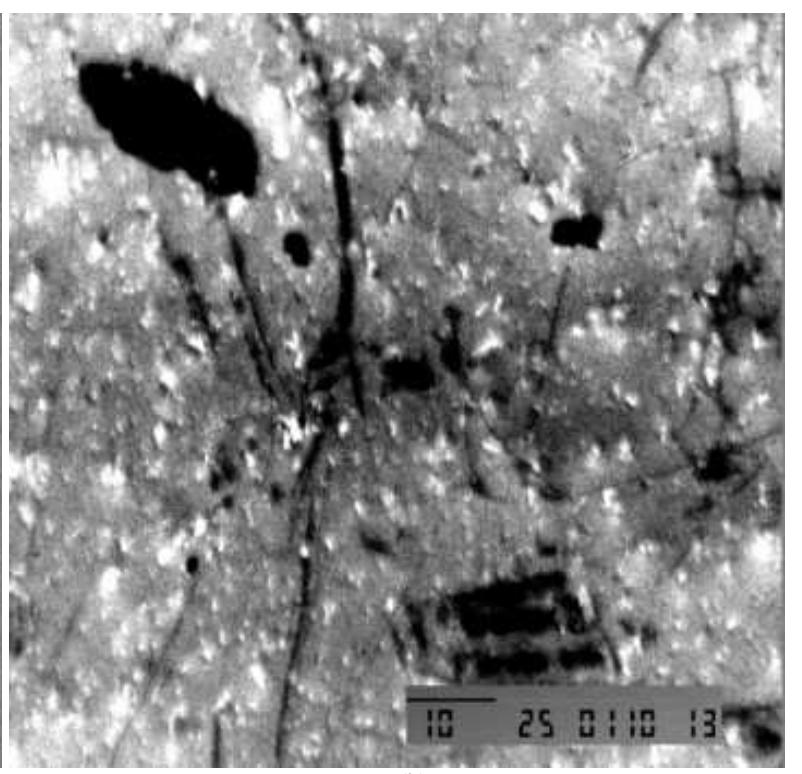

(b)

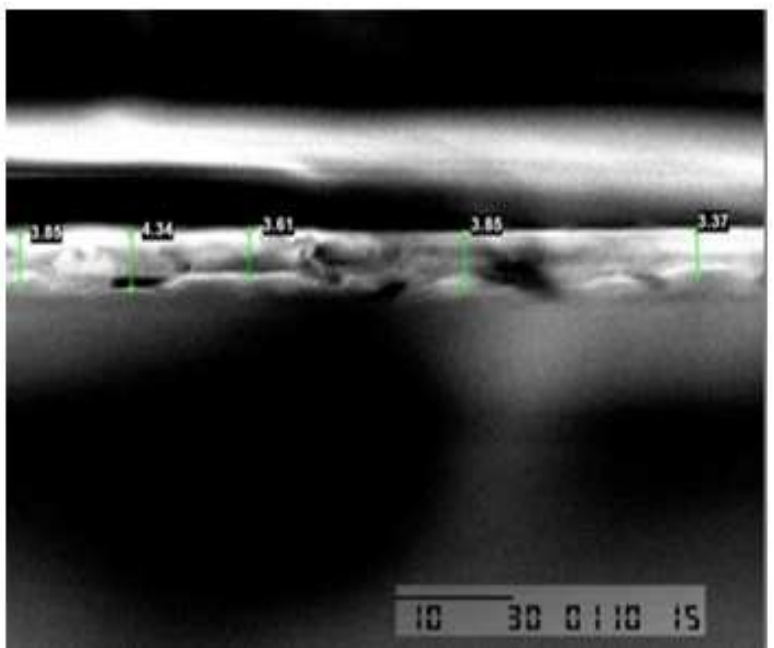

(b)

Fig. 4: SEM results with transverse positions along with coating thickness sizes for samples (a) as-deposited thin film (b) annealing at $120^{\circ} \mathrm{C}$ 


\section{Conclusion}

The XRD characterization gives a lattice constant value (5.782-5.919) $\AA$, this value is slightly different from the value obtained from the literature, because the film is subjected to stress and strain due to the annealing process. Grain size varies $(266,440$ $694,059) \AA$, the bulk of which is found in as-deposited thin film samples, since it is a direct solid of powder vapor during deposition and after annealing the grain size becomes finer. The average internal pressure is between $(0.364-3.247) \times 10^{9} \quad \mathrm{~N} / \mathrm{m}^{2}$ and the intermediate microstrain is $(2,864-25,943) \times 10^{-3}$, the sample under pressure as well as the largest microstrain i.e., the sample with annealing at $150^{\circ} \mathrm{C}$, this indicates that the annealing process gives force to the width of the resulting film as the temperature increases. Scanning Electron Microscope (SEM) shows sample surface images of PbS deposited thin film as well as samples with annealing at $120^{\circ} \mathrm{C}$ with $\times 1500$ magnification. Thin film thickness can also be determined based on $\times 2000$ transverse magnification, to obtain thickness for deposited thin films ranging between $(0.63-1.30) \mu \mathrm{m}$ and the thickness of thin film annealing at $120^{\circ} \mathrm{C}$ ranging between $(3.37-4,34) \mu \mathrm{m}$. The best quality thin film is with annealing at $120^{\circ} \mathrm{C}$, as it shows more peaks than other samples. Overall, it can be concluded that the annealing process gives effect to the crystal structure, grain size, pressure and strain on the crystal.

\section{Acknowledgement}

This study has been jointly supported by Indonesia's Ministry of Higher Education and Research, Universitas Lambung Mangkurat and Universitas Gadjah Mada. Upon this, the authors are thankful.

\section{Author Contributions}

Mustika Wati: She took part in all the phases of the study and contributed to the writing of the final manuscript.

Kamsul Abraha: Participated in every phase of the study and also contributed to the writing of the paper.

\section{Ethics}

The required academic procedures have been followed in writing this research note and therefore, it is original.

\section{References}

Choudhury, N. and B.K. Sarma, 2009. Structural characterization of lead sulfide thin films by means of X-ray line profile analysis. Bull. Mater. Sci., 32: 43-47.
Hass, G. and A.F. Turner, 1959. Preparation of Thin Film. In: Methods of Experimental Physics, Solid State Physics, Lark-Horovitz, K. and V.A. dan Johnson, (Eds.), Academic Press, New York dan London, pp: 122-133.

Iriani, Y., 2000. Pembuatan lapisan tipis TiN (Titanium Nitrida) dengan metode RF-sputtering dan karakterisasinya. Tesis S2, Program Pasca sarjana UGM, Yogyakarta.

Ji, Y., X. Ma, H. Zhang, J. Xu and D. dan Yang, 2003. Star-shaped $\mathrm{PbS}$ crystals fabricated by a novel hydrothermal method. J. Physics: Condensed Matter, 15: 7611-7615.

Smallman, R.E., 1991. Metalurgi fisik modern. Jakarta, Indonesia.

Sukarjo, A., 1991. Studi metode sintering untuk Pembuatan PbS, Skripsi. FMIPA UGM, Yogyakarta.

Wunderlich, B., 1976. Macromolecular Physics, Volume 2, Crystal Nucleation, Growth, Annealing. 1st Edn., Academic Press, New York, San Francisco, London. 